\title{
An infection control audit in 10 primary health-care facilities in the Western Cape Province of South Africa
}

\author{
Mphahlele $\mathrm{MT}^{1}$, Tudor $\mathrm{C}^{2}$, Van der Walt $\mathrm{M}^{1}$, Farley $\mathrm{J}^{2}$ \\ ${ }^{1}$ South African Medical Research Council, Pretoria, South Africa \\ ${ }^{2}$ School of Nursing, Johns Hopkins University
}

\begin{abstract}
In 2009, we conducted a cross-sectional descriptive study to evaluate environmental, administrative and personal infection control measures in ten primary health care facilities in Western Cape Province, South Africa. A standard data collection form was used to collect information on current infection control practices, and through structured interviews of administrative and clinical personnel.
\end{abstract}

Only 2 of 10 facilities had infection control plans specific to their facilities. Adequate supplies of personal protective equipment (respirators) in 8 of 10 facilities; no cohorting of tuberculosis (TB) patients was done and only half $(5 / 10)$ of the facilities had a designated infection control officer on site.

Infection control appears to be inadequate in the facilities studied. TB infection control needs to be strengthened including training and improving infrastructure in primary health care settings in the Western Cape Province.

\section{Key words}

Infection control, organization and administration; Primary Health Care; Tuberculosis

\section{Corresponding Author}

Mphahlele MT

Tuberculosis Epidemiology \& Intervention Research Unit, South African Medical Research Council

Private Bag X385, Pretoria 0001

Email: matsie.mphahlele@mrc.ac.za 


\section{Introduction}

In 2010, there were 8.8 million (range, 8.5-9.2 million) incident cases of tuberculosis (TB) globally, with the highest TB rates occurring in sub-Saharan Africa. ${ }^{1}$ South Africa has one of the highest TB burden in the world and is ranked third. ${ }^{1}$ According to the $\mathrm{WHO}$ an estimated 5.5 million South Africans were living with HIV/AIDS in 2009, with a co-infection rate of HIV estimated at $73 \%$ in all TB cases. ${ }^{2}$

Tuberculosis infection control in health care settings has received increased interest following the recent occurrence of multiple drug-resistant (MDR) and extensively drug-resistant (XDR) TB strains in populations of patients with immune systems affected by HIV. ${ }^{3}$ Inadequate infection control (IC) in hospitals poses a risk to patients and health care workers (HCWs) for the emergence and transmission of respiratory infectious diseases, such as TB. ${ }^{4}$ In most parts of the world, TB infection control in health care facilities remains inadequate despite the availability of international infection control guidelines. ${ }^{5}$ The situation is very different in low- and middle-income countries because these countries have high TB rates and limited resources. ${ }^{6,7}$ In these countries, even lowcost strategies to reduce TB transmission in health-care facilities are seldom implemented. ${ }^{8,9}$

The Western Cape is a South African province characterised by large farming rural population and a significant migrant population (also immigrant) from the Eastern Cape province. The Western Cape has a population of 5.3 million, reflecting an increase of 16.7\% between 2001 and 2007. There are 6 health districts. The Cape Town Metro District accommodates approximately $63 \%$ of the province's population, but there are large rural areas (farmlands) presenting challenges in health service delivery. In this province there are 428 public primary health care facilities (clinics and community health centres), some operated by the Department of Health, while others are operated by the City of Cape Town.

The Western Cape had a steady rise in TB incident cases between 1997 and 2008, though it stabilized from 2006. There were over 50,000 cases in 2008, with a case rate of approximately 1000 per $100,000 .^{10}$
Much higher rates of TB cases among HCWs of over 1180/100,000 HCWs have been reported. ${ }^{10,11}$ Provincial specific infection control policies for tuberculosis have been available, as is similar for other provinces of the country since $2006 .^{11}$

The aim of this study is to evaluate current administrative, environmental and personal protective control measures and also infrastructure in ten primary health care (PHCs) facilities.

\section{Methods}

\section{Study Setting}

A convenient sample representing ten PHCs in 8 different districts was selected for this study. Two out of ten PHCs are not in the Metro region, both of them are in the rural Boland region.

\section{Data collection}

On the day of the visit, senior administrative and clinical personnel were interviewed using a standardized questionnaire. The questionnaire sought to determine implementation and availability of administrative, environmental and personal protection policies as well as necessary infrastructure and supplies. Direct observation of infection control practices and infrastructure were completed during walking rounds, and recorded on a structured questionnaire. IC officers were asked to estimate the proportion of their work time spent in IC activities.

\section{Ethics approval}

Ethical approval was obtained from the South African Medical Research Council, Johns Hopkins University and the Western Cape Provincial Research Committee.

\section{Results}

\section{Description of the facilities}

All ten facilities are managed through the Department of Health and each treats tuberculosis patients. These facilities offer a wide range of health care services including antiretroviral (ARV) and radiology services on site. Administrative control measures reported during interviews are summarised in Table I and infection control measures observed and discussed during walking rounds are in Table II. 
Table I. Summary of administrative measures as reported during interviews

Primary Health Care Facilities

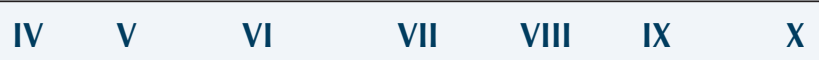

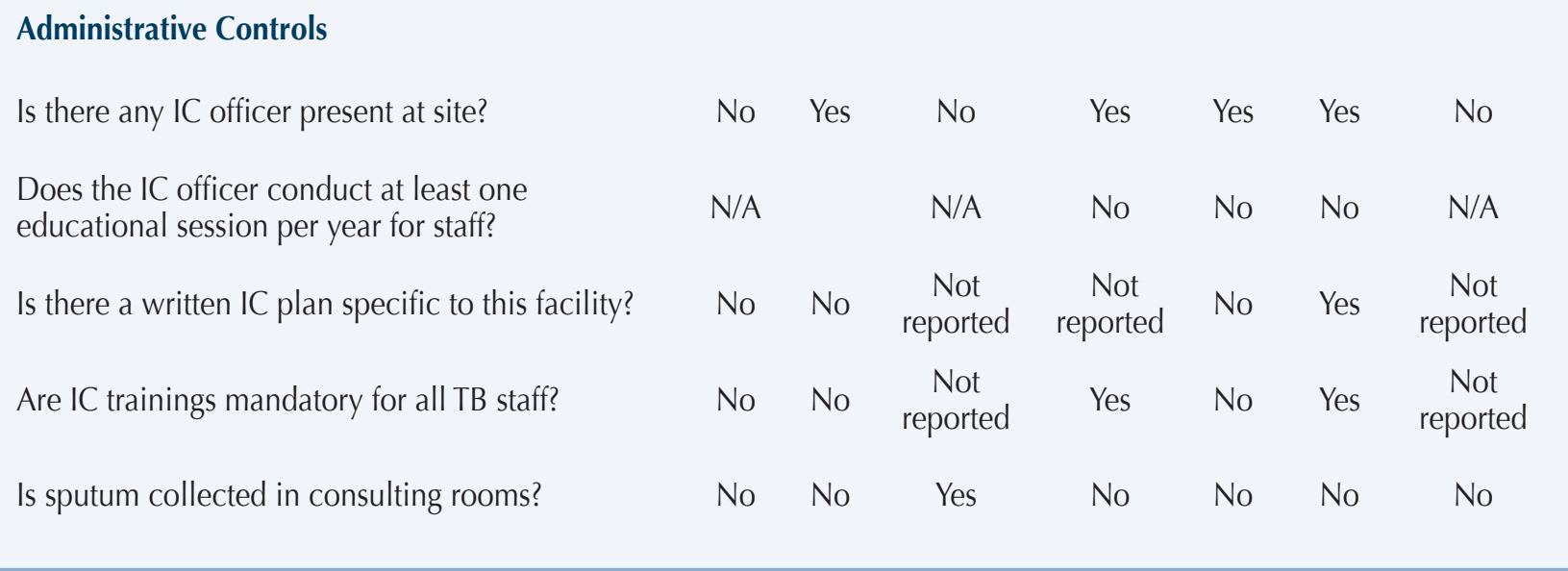

Table II. Infection Control measures observed and discussed during walking rounds

Primary Health Care Facilities

\begin{tabular}{|c|c|c|c|c|c|c|c|c|c|c|}
\hline \multirow[b]{2}{*}{ Administrative Controls } & & & & & & & & & & \\
\hline & I & II & III & IV & V & VI & VII & VIII & IX & $X$ \\
\hline Is sputum collected in the consulting rooms? & No & No & No & No & No & Yes & No & No & No & No \\
\hline $\begin{array}{l}\text { Are patients triaged upon entering the clinic without } \\
\text { waiting in a queue? }\end{array}$ & No & No & No & No & No & No & No & No & No & No \\
\hline Is there cohorting of smear +ve patients? & No & No & No & No & No & No & No & No & No & No \\
\hline
\end{tabular}

\section{Personal Controls} Are N-95 respirators used in the TB consulting room? Yes No No No No No Yes No No Yes Were HCWs observed using gloves in the TB consulting No Yes Yes No No No Yes Yes Yes Yes room?

\section{Environmental Controls}

Is upper room-UVGI present in the facility?

Are there windows open on both sides of the TB

$\begin{array}{llllllllll}\text { No } & \text { No } & \text { No } & \text { No } & \text { No } & \text { No } & \text { No } & \text { No } & \text { No } & \text { No } \\ \text { No } & \text { No } & \text { No } & \text { No } & \text { No } & \text { No } & \text { No } & \text { No } & \text { No } & \text { No } \\ \text { No } & \text { No } & \text { No } & \text { No } & \text { Yes } & \text { No } & \text { Yes } & \text { Yes } & \text { Yes } & \text { No }\end{array}$

Is mechanical ventilation in use anywhere?

No No No No Yes No Yes Yes Yes No

\section{Infrastructure}

Is the nurse's station an enclosed space inside the TB $\quad$ Yes $\quad$ Yes Yes Yes Yes Yes No Yes Yes Yes clinic with no IC precautions?

*UVGI =Ultraviolet germicidal irradiation 


\section{Staffing and Training to Support Infection Control}

Overall the number of full time registered nurses was higher as compared with seven of full time physicians and 11 enrolled nurses. Five (50\%) of the facilities had designated infection control (IC) officers on site. They all reported spending less than one day per week. Infection control training for TB staff was reported not compulsory in nine $(90 \%)$ of the facilities.

\section{Administrative and Personal Protective Measures}

Only two out of ten (20\%) facilities had IC plans specific to their facilities, no cohorting of patients in any of the facilities was practiced and TB patients shared the waiting rooms with other patients. The TB screening process was inadequate; none of the facilities triaged patients upon entering the facility. In terms of training in TB IC, two (20\%) facilities had mandatory IC training for all TB staff.

$\mathrm{N}-95$ respirators were available in 8 of $10(80 \%)$ facilities; however HCWs in only two facilities reported using N-95 respirators when collecting sputum. One $(10 \%)$ facility reported collecting sputum in the consulting room for TB patients.

\section{Environmental}

None of the facilities had the windows opened on both sides of the consultation rooms for TB patients, nor in the sputum collection rooms or X-ray rooms. Other rooms in the facilities had windows half open or just one window open on one side of the room, and there was easy passage of contaminated air to the nursing station. Four facilities used mechanical ventilation but none had a standby generator to use during power outages. None of the facilities had upper-room ultraviolet germicidal irradiation (UVGI).

\section{Infrastructure}

In terms of infrastructure, all but one had a nurse's station in the TB clinic with no or limited IC precautions which could be a serious risk to HCWs if the air flows from patient's rooms to the nurses' station. Some of the facilities are old and do not allow separation of patients.

\section{Discussion}

Our study shows that there is limited implementation of IC measures in PHC centres of the Western Cape.
The national guidelines are available but are not being followed, which may potentially affect patient and staff safety. Only 2 of $10(20 \%)$ facilities had IC plans specific to their facilities. None of the facilities separated the known smear-positive TB patients from other patients.

Training on TB infection control among the HCW was limited. Almost all of the facilities had compulsory training of TB staff in infection control. Lack of implementation of IC measures at these facilities could be due to less time devoted on IC activities and lack of education and training on TB infection control. These findings confirms similar findings from our previous study on infection control evaluation of MDR-TB hospitals in SA that infection control implementation in TB high-risk areas is poor. ${ }^{13}$

PHC facilities need to develop facility specific IC plans and have the use of respirators, open window policy and separation of coughing patients as standard practice, combined with health care workers having full knowledge about TB risks for themselves and patients. Amongst these, proper ventilation is one of the most effective and does not require monetary investment to implement. PHC facilities with suspected pulmonary TB patients should have plenty of light and windows that open to the outside and doors to other parts of the facility that are closed most of the time. In this study mechanical ventilation was used in four of the facilities studied but no maintenance plan was in place. Monitoring and ongoing maintenance of mechanical ventilation is crucial and requires both resources and expertise. Poorly maintained mechanical ventilation systems have been widely documented in resource rich settings and implicated in several TB outbreaks. Natural ventilation is always better than mechanical ventilation and this can be done through natural means e.g. air current through wind. ${ }^{12}$

\section{Conclusions}

TB infection control practices in the $10 \mathrm{PHC}$ facilities studied should be strengthened including training, improving infrastructure and provision of better ventilation systems in existing and new facilities in the Western Cape province. TB Infection control training should be part of pre-service and in-service training for all staff, including non clinicians and volunteers. 


\section{Acknowledgements}

We wish to thank those site and individuals who participated in this project. This study was supported by the Western Cape Department of Health, South Africa, and Fogarty International Center at the National Institutes of Health (grant number 5R25TW007506).

\section{References}

1. World Health Organization. Global Tuberculosis Control 2011. Geneva, Switzerland: World Health Organization; 2011.

2. World Health Organization. Global Tuberculosis Control: Epidemiology, Strategy, Financing. WHO Report 2009. Geneva, Switzerland: World Health Organization; 2009.

3. Howard AA, El-Sadr WM. Integration of tuberculosis and HIV services in sub-Saharan Africa: lessons learned. Clinical Infectious Diseases 2010; 50 (supplement 3): S238-S244. http://dx.doi.org/10.1086/651497

4. Lau JT, Fung KS, Wong TW, et al. SARS transmission among hospital workers in Hong Kong. Emerg Infect Dis 2004; 10: 280-286. http://dx.doi.org/10.3201/eid1002.030534

5. World Health Organization: World Health Organization: Guidelines for the prevention of tuberculosis in health-care facilities in resource-limited settings. WHO/CDS/TB/99.269 Geneva, Switzerland: World Health Organization; 2009.
6. Whitehead M, Dahlgren G, Evans T. Equity and health sector reforms: can low-income countries escape the medical poverty trap? Lancet 2001; 358: 833-836. http://dx.doi. org/10.1016/S0140-6736(01)05975-X

7. Makinen $M$, Waters $H$, Rauch $M$, et al. Inequalities in health care use and expenditure: empirical data from eight developing countries and countries in transition. Bull World Health Organ 2000; 78: 55- 65.

8. Harries AD, Maher D, Nunn P. Practical and affordable measures for the protection of health care workers from tuberculosis in low-income countries. Bull World Health Organ 1997; 75: 477-489.

9. Pai M, Kalantri S, Aggarwal AN, Menzies D, Blumberg $\mathrm{H}$. Nosocomial tuberculosis in India. Emerg Infect Dis 2006; 12: 1311-1318. http://dx.doi.org/10.3201/eid1209.051663

10. Naidoo S, Mahommed A. Knowledge, attitudes, behavior and prevalence of TB infection among dentists in the Western Cape. SADJ 2002; 57: 476-478.

11. O'Donnell MR, Jarand J, Loveday M, at al. High incidence of hospital admissions with multidrug-resistant and extensively drug-resistant tuberculosis among South African health care workers. Ann Intern Med 2010; 153(8): 516-522.

12. McCarthy $\mathrm{K}$, Mosendane T, Tellie M. Implementing TB Infection Control in health facilities, RHRU HIV Management Cluster, $1^{\text {st }}$ edn. 2009; page 13.

13. Farley JE, Tudor $\mathrm{C}$, Mphahlele $\mathrm{M}$, et al. A national infection control evaluation of drug-resistant tuberculosis hospitals in South Africa. Int J Tuberc Lung Dis 2012; 16(1): 82-89. http:// dx.doi.org/10.5588/ijtld.10.0791 